\title{
Análisis de la situación del VRAE. Su tratamiento por el Derecho Humanitario: ¿falta de estrategia?
}

Lesly Llatas Ramírez* http://dx.doi.org/10.21503/lex.v10i9.328

* Magíster en Derecho Constitucional y Derechos Humanos. Especialista en Derechos Humanos y Derecho Constitucional, profesora de la UAP.

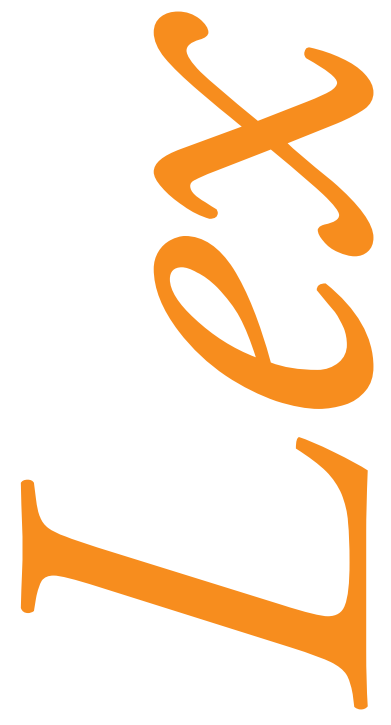





\section{ASPECTOS GENERALES}

Los hechos acontecidos últimamente, además de haber generado "intranquilidad e indignación" en la sociedad peruana, evidencian una falta de eficacia e idoneidad en la dirección del sector Defensa y la policía nacional, a la vez que la ausencia de una estrategia del Estado para poner fin a las acciones de violencia que tienden a multiplicarse en diversas zonas del país. La presencia de grupos armados organizados (terrorismo-narcotráfico) en provincias y distritos de los departamentos de Ayacucho, Huancavelica, Junín y Cusco; cercanos al valle de los ríos Apurímac y Ene - VRAE, ha obligado a declarar el estado de emergencia en ese extenso territorio de forma ininterrumpida, y permanece bajo el control de las FFAA por disposición del gobierno (Véase el art. $137^{\circ}$ de la CPP), lo que constituye una grave perturbación de la paz.

El panorama político se ha complicando aun más con el caso del Sub Oficial de la PNP César Vilca, quien fue rescatado "muerto y mutilado" en el VRAE por su padre don Dionisio Vilca - tras un ataque terrorista del que resultó no habido por la PNP ni las FFAA en incumplimiento de su deber, lo que motivó la especulación en el sentido que "lo dejaron sólo, luchando contra terroristas y narcotraficantes"; este hecho terminó por socavar la paciencia de los peruanos y especialmente de nuestros representantes en el Congreso de la República, dando lugar a la Moción de Censura presentada contra los ministros Alberto Otárola Peñaranda y Daniel Lozada de Defensa y del Interior, respectivamente. Analicemos a continuación algunas consideraciones de la moción presentada por diversas bancadas de oposición en el parlamento, que ha provocado una severa crisis en la bancada oficialista (de gobierno), dando la impresión de estar a punto de una disolución parcial.

\section{DE LA RESPONSABILIDAD POLÍTICA DE LOS MINISTROS DE ESTADO}

La responsabilidad política, que es una garantía del estado de derecho, se establece mediante la valoración de la idoneidad o capacidad de gobernantes y/o funcionarios públicos para el ejercicio y desempeño de funciones en salvaguarda del bienestar, la seguridad y la paz de la sociedad. 
La responsabilidad política:

1. Falta de idoneidad y capacidad.- Por falta de idoneidad debemos entender que el funcionario de Estado no es la persona idónea, "competente", para ejercer un cargo público o de gobierno o, en su defecto, no es la indicada para el desempeño de una función especializada, como es el caso de los Despachos de Defensa y Ministerio del Interior; dos carteras ministeriales que requieren adecuada especialización de funcionarios que conozcan desde adentro (estructura orgánica) la problemática institucional y que no exterioricen en sus quehaceres "improvisación". Por su parte, la capacidad implica el desarrollo de habilidades, iniciativas, estrategias, planteamientos y opiniones pertinentes; lo cual solo es posible cuando el funcionario goza de pleno conocimiento del tema. En conclusión: colocar a personas sin conocimientos o sin idoneidad para que desempeñen funciones públicas, es un atentado al buen gobierno y daña la democracia.

2. Otro aspecto que implica responsabilidad política, deviene de haber desplazado miembros de las FFAA y de la PNP, sin la debida previsión, es decir, sin el conocimiento estratégico del territorio, a sabiendas que es una zona minada y de alto riesgo, y sobre todo, que los terroristas y narcotraficantes dominan el VRAE. Cabe preguntarse: ¿cómo se desplaza personal militar y policial sin el debido equipamiento, dando la impresión lamentable de que exploraban dicho territorio por primera vez? Ello ha quedado demostrado con la —casi milagrosa- reaparición del sub oficial Luis Astuvilca, quien logró salir de ese territorio por sus propios medios y capacidad de supervivencia, y es que, como bien se dijo en un reportaje periodístico, la selva del VRAE tiene "ojos y oidos". Una alternativa sería tomar el ejemplo de la operación Chavín de Huántar, en cuya aplicación — para poder rescatar a los 72 rehenes, sin negociación política-económica con los terroristas- se previó un entrenamiento estratégico, con réplica de la zona, en ese caso la embajada donde se iba a incursionar.

La problemática del VRAE no es de ahora, el entrenamiento estratégico debió comenzar hace muchos años atrás, y con réplica en nuestras selvas para conocer el territorio y dominarlo. Alguna sugestión debió haberse hecho al respecto, y asi evitar la reacción tardía tras la toma de rehenes, secuestros de niños, violaciones sexuales, entre otras graves violaciones a los derechos humanos.

3. Otro de los aspectos a destacar, y quizás el más importante, es que el Estado peruano no ha destinado el suficiente presupuesto para mejorar las condiciones de nuestras FFAA y PNP. Ello implica que nuestros valerosos combatientes no estén premunidos de todas las condiciones para la lucha contra los narcoterroristas. Esta situación coloca a las fuerzas armadas en una situación indignante y vergonzosa ante el país y, eventualmente, en desventaja ante el terrorismo. Ello es responsabilidad del gobierno y alcanza a diversos sectores, por ejemplo, el ministerio de Economía y finanzas. 
4. Es reiterativo, igualmente, el aparatoso reconocimiento de heroísmo a nuestros combatientes como si la vida valiese solo eso: "una placa"; pomposos funerales con el propósito de dejar en el olvido la ineficacia e ineptitud de los ministros de Defensa y del Interior. No podemos pagar tan alto precio a costa de nuestra dignidad como peruanos, la sociedad no puede sumergirse en un mundo de hipocresía.

La vida es un derecho humano, sin el cual no es posible la existencia de nada más. Si bien en un enfrentamiento el riesgo mayor es la pérdida de la vida, no menos cierto es que, el hecho de "abandonarlos" en el campo de batalla refleja un comportamiento cobarde como no se ha visto en ninguna otra ocasión en el Perú. Si el hecho se atribuye a una "emboscada", es decir, a colocar un cuerpo muerto para tender una emboscada, es lógico considerar como cierta esa eventualidad, pero también es lógico pensar que si se trata de enfrentar una emboscada, no cabe desplegar refuerzos sino una respuesta militar dimensionada. En otras palabras, la aplicación de acciones militares estratégicas.

Sigamos analizando la problemática del VRAE, a la que se debería responder mediante una operación militar y ya no policial. Si bien es cierto que la PNP tiene dos direcciones especializadas: DIRCOTE (Dirección contra el terrorismo) y DINANDRO (Dirección antidrogas) ${ }^{1}$, a través de las cuales se han generado "operaciones especiales" para combatir

\footnotetext{
DIRCOTE PNP es el Órgano sistémico, técnico-normativo y ejecutivo de la PNP, encargado de prevenir, investigar, denunciar y combatir el Delito de Terrorismo cometido por elementos o grupos nacionales o extranjeros. La DIRCOTE, cuenta con las Divisiones de Investigación de Terrorismo Metropolitano, Terrorismo Internacional, Terrorismo Regional (VRAE, Huallaga), de Operaciones Especiales e Investigaciones Especiales, estamentos que apoyados por el personal administrativo de Criminalística, la Escuela de Capacitación, Operaciones Psicológicas, logran estratégicamente hacer frente a los remanentes de las organizaciones terroristas que operan en el VRAE y el Huallaga, y en otros puntos del país, y vienen reorganizándose y ganando adeptos para sus intereses.
}

Como Dirección Especializada y Sistémica de la Policía Nacional del Perú, planear, organizar y ejecutar operaciones policiales a nivel nacional e internacional para combatir el trafico ilícito de drogas y delitos conexos; previniendo, investigando y denunciando estos delitos; protegiendo a la sociedad de la drogadicción, coadyuvando al desarrollo social, mediante un servicio de excelencia con personal especializado, basado en los principios de integridad, solidaridad y justicia. Entre sus funciones está el de prevenir la comisión de actividades terroristas provenientes de elementos o grupos nacionales o extranjeros, con los medios e información disponibles; investigar y denunciar las actividades delictivas con propósito terroristas, en todas sus formas y modalidades; mantener información actualizada y producir inteligencia que permita cumplir la misión asignada; intervenir en la verificación y comprobación del domicilio de los condenados por delito de terrorismo que solicitan el beneficio penitenciario de la liberación condicional; así como controlar e inspeccionar el cumplimiento de las reglas de conducta impuestas a los beneficiarios.

DINANDRO. Como Dirección Especializada y Sistémica de la Policía Nacional del Perú, planear, organizar y ejecutar operaciones policiales a nivel nacional e internacional para combatir el trafico ilícito de drogas y delitos conexos; previniendo, investigando y denunciando estos delitos; protegiendo a la sociedad de la drogadicción, coadyuvando al desarrollo social, mediante un servicio de excelencia con personal especializado, basado en los principios de integridad, solidaridad y justicia. Ser una Dirección Especializada de la Policía Nacional del Perú, de reconocido prestigio nacional 
el narcoterrorismo en la zona de conflicto VRAE; sin desmerecer a la institucionalidad de la PNP, cuyo mandato constitucional es la de garantizar el orden público del país, se puede afirmar que la PNP no cuenta con la debida preparación, entrenamiento y equipamiento para esta clase de enfrentamientos, y que más bien sus funciones y su importancia se anulan así para el desarrollo del país. Debemos tomar conciencia de errores como el de desplazar a jóvenes sub oficiales sin preparación a la zona de conflicto. Se ha demostrado, además, la escasa exploración del territorio para contraatacar y, el error más grave, la comisión de "dejar solos a los combatientes". Por lo menos esa es la lectura que tenemos y que, tanto el ministro del Interior como el de Defensa no han sabido explicar satisfactoriamente a la ciudadanía. En ese sentido, nos preguntamos: ¿Por qué se ha permitido el desplazamiento de sub oficiales tan jóvenes y sin la debida preparación y entrenamiento de la PNP y FFAA en la zona del VRAE en este tipo de conflictos? De ahí deriva la responsabilidad política de los funcionarios de Estado.

En un artículo de Samuel P. Huntington titulado "Ningún otro país obliga a sus oficiales más antiguos a gastar tanto tiempo en estudiar presupuestos y tan poco tiempo en estudiar estrategia", hace una delimitación conceptual de lo que se entiende por una operación militar. Veamos:

El concepto esencial de las operaciones militares permite hacer los siguientes enunciados inequívocos, dice el autor:

1) El principio fundamental de una operación militar es la destrucción y/o neutralización de las fuerzas en oposición.

2) Generalmente, esta destrucción y/o neutralización de fuerzas en oposición solo puede ser cumplida mediante la confrontación.

3) Solo los enfrentamientos basados en una adecuada inteligencia permitirán obtener los objetivos planteados por el Estado. Estos objetivos deben estar claramente definidos en todos los sectores del gobierno de turno, pues el problema (en este caso el del VRAE) no reclama únicamente una solución militar policial, sino de todos los actores políticos del Estado. Si se logra

e internacional, que aplica adecuadas estrategias para garantizar una efectiva lucha contra el tráfico ilícito de drogas y delitos conexos; dentro del marco de la ley e irrestricto respeto de los derechos humanos. Entre sus funciones:

1. Planea y ejecuta las acciones de interdicción contra el tráfico ilícito de drogas en el Perú.

2. Investiga y denuncia a las personas dedicadas a la producción y comercialización de drogas, desvío de insumos químicos y lavado de activos.

3. Realiza acciones de inteligencia que permita la destrucción de los laboratorios clandestinos de elaboración de droga y el hallazgo de cultivos de amapola.

4. Realiza acciones de interdicción terrestre, helitransportada, fluvial y lacustre.

5. Asume el control y la seguridad para que el personal del proyecto especial CORAH realice las acciones de erradicación de cultivos ilícitos de hoja de coca. 
que esto se entienda y que se trabaje multisectorialmente, se podrán alcanzar los objetivos que forman parte de la politica de Estado

\section{En el artículo de Huntington se señala además que:}

- Resulta conveniente indicar que la acción de gobierno se debe mirar como una inversión en procura de la pacificación nacional, y no simplemente como operaciones militares aisladas que no van a tener éxito en la actual situación de operatividad.

- Se requiere tropa altamente entrenada, con equipamiento moderno, helicópteros para transporte de personal y material, así como aviones ligeros como el Super Tucano; por otro lado, un planeamiento general al más alto nivel para poder conducir las operaciones en el nivel Supra Estratégico (Político-Jurídico) tanto militar como no militar (Consejo de Defensa Nacional), Militar Policial (CCFFAA-PNP) y a nivel táctico en el área de operaciones que, pese a su importancia, es poco atendido en sus reales necesidades y fuertemente cuestionado: se exige resultados sin atender requerimientos solicitados o con atención limitada, lo que lleva a la improvisación y a resultados insatisfactorios.

\section{Concluyendo:}

- El autor pone en evidencia "lo que no tenemos" para asumir el enfrentamiento. Como bien se puede colegir, resolver la problemática del VRAE es una tarea colectiva que demanda la participación de todos los sectores de la sociedad. Estamos de acuerdo en que ello responde incluso a un Plan Nacional operativo como se ha venido difundiendo en los medios de comunicación; mediante el cual cada sector ayudará desde el ámbito de sus funciones y competencias.

- Una estrategia a seguir, es el retiro de tropas con miembros de la PNP porque ellos están para garantizar el orden interno, podrían más bien brindar resguardo a la población aledaña a la zona de conflicto. Creo que su inteligencia sería más provechosa a ese nivel que en las operaciones militares porque no forman parte de su competencia. Por consiguiente, haberlas conducido hasta ahi ha sido una decisión errada del gobierno y tendrá que asumir el costo político por ello.

- En el caso Chavín de Huántar, la PNP coadyuvó al mantenimiento del orden al exterior de la entonces embajada de Japón donde estaban secuestrados 72 rehenes en manos de terroristas, dejando a las FFAA la operación militar y estrategia para la liberación de los mismos; el contexto en que nos encontrábamos era un conflicto armado interno inmerso en un gobierno autoritario. 


\section{DE LA MOCIÓN DE CENSURA A LOS MINISTROS DE ESTADO}

Diversas bancadas de la oposición en el Parlamento presentaron la Moción de censura No 2047, con fecha 03 de Mayo de 2012, en aplicación del artículo $132^{\circ}$ de la CPP y del artículo $86^{\circ}$ del reglamento del Congreso de la República el cual señala que:

Los Congresistas de la República que suscriben, al amparo del artículo 132 de la Constitución Política del Perú y del artículo $86^{\circ}$ del Reglamento del Congreso de la República, proponemos a la Representación Nacional la siguiente Moción de Censura:

\section{CONSIDERANDO:}

Que, con fecha 18 de abril del año en curso, los ministros de Defensa, Alberto Otárola, e Interior, Daniel Lozada, acudieron al Congreso a fin de informar sobre la Operación Libertad, falsamente llamada "una operación impecable" que tiene en su haber al menos, ocho muertos entre las Fuerzas del Orden, desaparecidos y ningún terrorista detenido. La debilidad y falta de estrategia y liderazgo frente al crecimiento de acciones violentistas que se aprovechan de la crisis interna y división resultado de la débil política antisubversiva del gobierno.

Que, nuestras Fuerzas Armadas y Policía Nacional han sido enviadas a combatir con chalecos antibalas sin el blindaje apropiado, sin raciones alimenticias suficientes, e inclusive existen serias denuncias sobre el abandono de nuestros efectivos en el campo de batalla, quedando a merced de los terroristas.

Que, inclusive se ha enviado helicópteros sin el debido equipamiento a la zona, lo cual ha producido la muerte a manos de los terroristas de la piloto Nancy Flores Páucar, consecuencia de una falta de política clara y decidida de las carteras del Interior y Defensa en la lucha anti terrorista.

Que, el fracaso del gobierno en la lucha contra la subversión en el VRAE ha llegado a límites insostenibles, se informa oficialmente que los terroristas se encuentran cercados, pero luego éstos ofrecen entrevistas en la zona a los periodistas que cubren la noticia, sin encontrarse con ningún efectivo de nuestras Fuerzas Armadas o Policía Nacional patrullando la zona.

Que, hemos visto, conmovidos, cómo el valeroso policía Astuquilca, luego de varios días en medio de la selva, ha llegado por su propio pie a Postaquiato sin que sea rescatado por ningún miembro de las fuerzas del orden, y fueron pobladores de la zona quienes lo llevaron hasta el puesto de Kiteni. Como si no fuera suficiente, pocos días después el padre del policía César Vilca, quien estaba desaparecido, encontró, por sus propios medios, el cuerpo abandonado de su propio hijo a 300 metros de la zona de enfrentamiento. 
Que, la nula capacidad del gobierno para combatir la subversión ha puesto en jaque la seguridad nacional y pone en riesgo la vida de nuestra población.

\section{MOCIÓN DE CENSURA}

Censurar a los ministros de Defensa, Alberto Otárola Peñaranda y del Interior, Daniel Lozada Casapía, por su comprobada incapacidad, falta de liderazgo y estrategia para conducir sus respectivas carteras, originando, entre otras graves negligencias de consecuencias irreparables, la muerte y abandono de miembros de nuestras Fuerzas Armadas y Policía Nacional, así como la exposición de toda la población al flagelo violentista del terrorismo.

Una moción que el día de hoy², pareciera haber conseguido los votos para censurar a ambos ministros por incurrir en una grave responsabilidad política atribuida a la fallida "operación de libertad" Pues de acuerdo con la nota de prensa del diario el Comercio, de fecha 03 de mayo de 2012, se publicó algunas de las razones evaluadas por los expertos que habrían dado por conclusión el fracaso de la "operación libertad en Kiteni”3. Esta operación

08 de Mayo de 2012, en que se escribe este artículo siguiendo los acontecimientos del mismo. De acuerdo con lo informado por el centro de noticias del Congreso de la República se tiene que, la Presidencia del Congreso fijará la fecha del debate de la moción de censura a los ministros de Defensa y del Interior, dentro del cuarto y décimo día de su presentación, conforme a la Constitución y el Reglamento del Poder Legislativo.

La moción, según se informó, fue presentada el 3 del presente, por lo cual el último día para su debate es el domingo 13. Respecto al debate de esa moción, la Junta de Portavoces, que se reunió esta tarde, dejó en manos de la Presidencia del Poder Legislativo para que proceda de acuerdo a la Constitución y el Reglamento.

3 Desde el secuestro de 36 empleados del proyecto Camisea en la provincia cusqueña de Kiteni, hace poco más de tres semanas, ocho agentes de las Fuerzas Armadas (FFAA) y de la Policía Nacional del Perú (PNP) cayeron abatidos por balas senderistas. De los logros de las fuerzas conjuntas no se conoce mucho: los rehenes de la columna senderista llegaron caminando. El cabecilla ‘Gabriel' (Martín Quispe Palomino) fue hallado por un equipo de periodistas. El suboficial PNP Luis Astuquillca sobrevivió y llegó por su cuenta a Kiteni, acompañado de nativos. Y el lamentable hallazgo del cadáver de César Vilca fue posible gracias al arrojo de su padre, conducido al monte por dos lugareños. El hallazgo es ampliamente negativo y delata no solo carencias en el equipamiento de las fuerzas combinadas y errores en la estrategia de la operación Libertad, sino también serias responsabilidades políticas en los sectores Defensa e Interior. La estrategia de combate en esta zona colindante al VRAE y en esa precisa región debe replantearse necesariamente y las autoridades encargadas de la lucha contra el narco senderismo, ser removidas, coinciden los expertos consultados por elcomercio.pe.

NADA POSITIVO. Para el exministro del Interior, general PNP (r) Remigio Hernani, el saldo de la operación es "totalmente negativo" y solo queda resaltar "el valor de los comandos y su alta preparación". En tal sentido, recordó que el presidente del Consejo de Ministros, Óscar Valdés, tenía a Alberto Otárola (ministro de Defensa) como viceministro del Interior y a Daniel Lozada (ministro del Interior) como jefe del gabinete de asesores del mismo ministerio. "Con ellos se dio de baja a 30 generales de la PNP y a muchos oficiales entre quienes había gente valiosa. También se fracasó en el tema de implantar servicio policial voluntario, y no hay ninguna mejora económica. Hay una profunda desmoralización en el cuerpo", comenta Hernani. A pesar de que pasaban los días desde el secuestro de los trabajadores de Camisea y no había avances, el presidente Ollanta Humala dijo ante los rehenes liberados que la operación había sido "impecable". Para Hernani, la responsabilidad política es también de ambos ministros: "Ellos han permitido que digan que es una operación impecable. Al presidente no se le puede mentir, para que no cometan esos deslices".

NI RADIOS. El especialista en narco senderismo Pedro Yaranga coincidió en responsabilizar a los mandos superiores de la operación y apuntar los errores tácticos del ingreso de las tropas a la zona de ceja de selva. Yaranga dijo a elcomercio.pe 
tan cuestionada responde al hecho de garantizar la liberación y seguridad de los 36 rehenes que son trabajadores de la empresa transnacional Consorcio Camisea Transportadora de Gas del Perú (TGP), secuestrados en el centro poblado de Kepashiato ( que no es VRAE con exactitud, pero si una zona con presencia del terrorismo) por miembros de Sendero Luminoso. Kepashiato se encuentra ubicado en el distrito de Echarate, provincia de la Convencióndepartamento del Cusco. El gobierno señaló que la operación de liberación fue impecable y no fue necesario ningún tipo de negociación para liberarlos. Sin embargo, los medios de comunicación han propalado que habría mediado una compensación económica.

Si consideramos fríamente el tema, lo primero que nos preguntaríamos sería ipor qué tuvimos éxito en la liberación de 36 rehenes de las manos del terrorismo y no se tuvo éxito en el rescate de los niños secuestrados en el VRAE tras el enfrentamiento con los narco terroristas? ¿Es que se pagó el precio de un rescate?

que las patrullas no contaban con comunicación por radio entre ellas, solo con la base en Kiteni, y que en la espesura de la región incluso podrían haber llegado a enfrentarse entre sí. De hecho, la ejecución de la operación ha supuesto avances y retrocesos en su ejecución y, al final, la suspensión de actividades en el rescate de Vilca. Prueba de ello fue el asesinato de dos policías y un militar el 27 de abril, en Alto Inkari. Asimismo, las versiones sobre la suspensión del rescate de Vilca por órdenes superiores indicaban que ya no había claridad en la ruta a tomarse. "Lo que se hizo el 27 es algo que solía hacerse más o menos hace 29 años, cuando se desconocía al enemigo. Al momento en que se debilitaba a las fuerzas del orden, los senderistas minaban la zona y los soldados morían al volver a recorrerla", indicó Yaranga.

NUNCA ABANDONES A TUS CAIIDOS. "Se ha roto una regla de oro de la conducción del liderazgo en combate: nunca abandones a tus heridos, nunca abandones a los caídos en acción de armas. Ellos se merecen los mayores honores por ofrendar la vida por la patria", dijo a elcomercio.pe el congresista fujimorista y vicealmirante (r) de la Marina de Guerra del Perú, Carlos Tubino. Para el legislador, las patrullas en el lugar dejaron de ser "predeciblemente impredecibles" y caminar por las trochas en la selva fueron parte de los mayores errores de la operación: "Se tiene que caminar a campo traviesa, donde es más difícil que haya campos minados". En vista de que las fuerzas combinadas fracasaron al entrar a la zona, ¿qué papel deberían haber jugados los nativos del lugar? Para Yaranga se menospreció el apoyo de la gente y se pudo haber volanteado por radio Quillabamba pedidos de apoyo a los lugareños. Una vez más, el Estado de espaldas a la población en estas alejadas zonas.

NO HAY DECISIÓN POLÍTICA NI MILITAR. ¿Vale la pena replantear la formación de patrullas de las FFAA y PNP para operar en el lugar? Las "operaciones conjuntas" son peyorativamente llamadas en el argot castrense como "operaciones rejuntas” señala Tubino y ello no es gratuito. En las operaciones conjuntas, en la práctica, cada cuerpo mantiene su unidad táctica y sus protocolos operativos no se logran coordinar por falta de entrenamiento conjunto. En la cancha, nuestras fuerzas no han podido movilizarse con chalecos y pertrechos que suman 15 kilos de peso. En opinión de Yaranga, no porque los equipos no sean idóneos, sino porque los soldados y comandos no entrenan con el referido equipamiento puesto. Entonces, su equipamiento continúa en pésimo estado. "Hemos visto personal combatiendo únicamente con un fusil cuando lo clave es tener mejores equipos que el enemigo en este terreno difícil, usar lanzagranadas. No se ve la decisión política ni militar de apoyar con el fuego a nuestras patrullas", afirma Tubino, quien añade que el apoyo con fuego aéreo de la FAP ha brillado por su ausencia.

Peor aún. El legislador señala que se ha dispuesto 1375 millones de soles para el orden interno y lucha contra el narco senderismo, pero en las FFAA, según informes extraoficiales, la mayor parte del dinero se invertirá en equipamiento para el frente externo. En sencillo: se preferirá comprar tanques para repeler fantasmales invasiones de países vecinos que mejorar el armamento de las patrullas en el VRAE. "O se reparará aviones MIG 29, cazas usados para situaciones de superioridad aérea, en lugar de mejorar las aeronaves de apoyo a fuerzas terrestres", afirma Tubino. A estas horas, en el Legislativo se debate la citación a los ministros del Interior y Defensa y, de darse, podría culminar en la censura de ambos. Sin embargo, ¿`con ello podremos esperar un nuevo rumbo en el VRAE contra el enemigo número uno de la paz del Perú?- Por otro lado, si Astuquillca salió de la selva por cuenta propia y Vilca fue hallado por su padre, ¿qué respaldo pueden sentir las fuerzas del orden en el VRAE? Los consultados coincidieron en que solo la sensación de abandono puede cundir entre sus filas. 


\section{ZONA DE CONFLICTO DEL VRAE Y SU CARACTERIZACIÓN COMO CONFLICTO ARMADO INTERNO}

La zona de conflicto en el VRAE es una caracterización de lo que en el ámbito del Derecho Internacional Humanitario - en adelante $\mathrm{DIH}$ - se llama conflicto armado no internacional o interno ${ }^{4}$. Existe un desplazamiento de tropas a la zona del VRAE, declarada en estado de emergencia permanente, en cuyo territorio se ha comprobado la presencia de un grupo armado de narcoterroristas, organizado por los "Quispe Palomino", con un mando responsable y zonas minadas que ponen en riesgo la vida no sólo de las fuerzas del orden sino también de la población civil, especialmente de nuestros indígenas. Sería conveniente señalar que los enfrentamientos en el VRAE reunen las dos condiciones que la jurisprudencia internacional ha establecido para la calificación de un CANI: Intensidad de las hostilidades y organización del grupo armado.

El Perú atraviesa, en los momentos actuales, uno de sus más difíciles enfrentamientos, toda vez que en los años 80 podíamos hablar de una lucha frontal solo contra la subversión, mientras que ahora la situación es diferente pues se han unido dos flagelos: terrorismo y narcotráfico que son una amenaza latente contra la institucionalidad democrática y el orden constitucional. Desconocer que la situación del VRAE es un conflicto armado no internacional o interno es ignorar la vigencia de los Convenios de Ginebra y sus protocolos 5 que ha adscrito el Perú;

4 Definición de Conflicto Armado. De acuerdo con el diccionario de Derecho Internacional de los conflictos armado, esta expresión genérica se aplica a diferentes tipos de enfrentamiento, es decir, a los que puede producirse:

- Entre dos o mas entidades estatales (V. guerra)

- Entre una entidad estatal y una facción disidente ( V. conflicto armado no internacional)

- Entre dos etnias diversas al interior de una entidad estatal ( V. conflicto armado no internacional o también llamado conflicto armado interno internacionalizado

- Entre una entidad estatal y una entidad no estatal. No todos los conflictos entre entidades estatales y no estatales son guerras de liberación nacional. El conflicto entre el Estado Peruano y el grupo de los Quispe Palomino es un CANI entre una entidad estatal y una no estatal pero no es una guerra de liberación nacional.

5 Los Convenios de Ginebra y sus Protocolos adicionales son tratados internacionales que contienen las principales normas destinadas a limitar la barbarie de la guerra. Protegen a las personas que no participan en las hostilidades (civiles, personal sanitario, miembros de organizaciones humanitarias) y a los que ya no pueden seguir participando en los combates (heridos, enfermos, náufragos, prisioneros de guerra, detenidos).

Los Convenios de Ginebra y sus protocolos adicionales son la piedra angular del derecho internacional humanitario, es decir el conjunto de normas jurídicas que regulan las formas en que se pueden librar los conflictos armados y que intentan limitar los efectos de éstos. Los convenios y sus protocolos establecen las medidas que se debe tomar para prevenir o poner fin a cualquier infracción de dichos instrumentos. Contienen normas estrictas en relación con las llamadas "infracciones graves". Se debe buscar, enjuiciar o extraditar a los autores de infracciones graves, sea cual sea su nacionalidad.

Los Convenios de Ginebra entraron en vigor el 21 de octubre de 1950. Fueron ratificados paulatinamente a lo largo de las décadas: 74 Estados ratificaron los Convenios en la década de 1950, 48 Estados lo hicieron en la de 1960, 20 Estados, en la de 1970, y otros 20, en la de 1980. Veintiséis Estados ratificaron los Convenios a comienzos de los años 1990, sobre todo después de la disolución de la Unión Soviética, Checoslovaquia y ex Yugoslavia. Gracias a siete nuevas ratificaciones que se concretaron a partir del año 2000, el total de Estados Partes se elevó a 194, lo que significa que los Convenios de 
asimismo, desconocer la aplicación del derecho internacional humanitario, normatividad que rige los conflictos armados internacionales (CAI) o los Conflictos Armados No Internacionales (CANI), es decir, conflictos internos.

Las expresiones "derecho internacional humanitario", "derecho de los conflictos armados" $y$ "derecho de la guerra" pueden considerarse como equivalentes, y la elección de una u otra dependerá esencialmente de las costumbres y del público. Así, las organizaciones internacionales, las universidades o los Estados emplearán más bien la expresión "derecho internacional humanitario" (o "derecho humanitario"), mientras que, en las fuerzas armadas, las otras dos son las más utilizadas.

El DIH o derecho de los conflictos armados se define como el conjunto de normas del derecho internacional de origen convencional o consuetudinario, específicamente destinadas a regular problemas acaecidos en conflictos armados internacionales o no internacionales. Estas normas restringen, entre otras cosas, la elección de las partes en conflicto en cuanto a los métodos, medios y objetivos de combate en una situación operacional determinada. Sus disposiciones se aplican en general a: ${ }^{6}$

a) Las hostilidades en general

b) La conducción del combate por las FFAA

c) El comportamiento de los combatientes

d) La protección de las personas afectadas por el conflicto

e) El derecho a la neutralidad que rige los derechos y deberes respectivos de los Estados beligerantes y de los Estados neutrales.

El DIH, en el marco de su principio de protección obliga a los Estados a responder ofreciendo protección y asistencia a las víctimas y a velar por la eficacia de esta asistencia. Al margen de la evolución de la guerra moderna, las personas siguen sufriendo en los conflictos armados como en otras situaciones de violencia, y necesitan protección. Los Estados tienen

Ginebra ahora son aplicables universalmente.

En las dos décadas siguientes a la aprobación de los Convenios de Ginebra, el mundo presenció un aumento en el número de conflictos armados no internacionales y de guerras de liberación nacional. En respuesta a esta evolución, en 1977 se aprobaron dos Protocolos adicionales a los cuatro Convenios de Ginebra de 1949. Estos instrumentos refuerzan la protección que se confiere a las víctimas de los conflictos internacionales (Protocolo I) y de los conflictos no internacionales (Protocolo II) y fijan límites a la forma en que se libran las guerras. El Protocolo II es el primer tratado internacional dedicado exclusivamente a las situaciones de conflicto armado no internacional. En 2005, se aprobó un tercer Protocolo adicional, que establece un emblema adicional, el cristal rojo, que tiene el mismo estatuto internacional que los emblemas de la cruz roja y de la media luna roja.

6 Pietro Verri - CICR.- Diccionario de Derecho Internacional de los conflictos armados. Ginebra, 1998. 
la obligación de actuar ante el sufrimiento humano, respetando el principio de protección de las víctimas.

El DIH o derecho de los conflictos armados, o derecho de la guerra comprenden dos ramas distintas:

1. El derecho de Ginebra o derecho humanitario propiamente dicho, cuyo objetivo es proteger a los militares puestos fuera de combate y a las personas que no participan en las hostilidades, en particular la población civil.

2. El derecho de La Haya o derecho de la guerra, por el que se determinan los derechos y las obligaciones de los beligerantes en la conducción de las operaciones militares y se limita la elección de los medios para perjudicar al enemigo.

Debemos señalar que estas dos ramas del DIH no son totalmente independientes: la finalidad de algunas normas del derecho de La Haya es proteger a las víctimas de los conflictos, la del derecho de Ginebra es limitar la acción de los contendientes en las hostilidades.

Con la aprobación de los Protocolos adicionales de 1977, en los que se han reunido ambas ramas del $\mathrm{DIH}$, hoy ésta distinción sólo tiene un valor histórico y didáctico.

\subsection{Marco Legal del Conflicto Armado No Internacional (CANI)}

\section{Convenios de Ginebra de 1949}

El articulo $3^{\circ}$, que es común a los cuatro convenios de Ginebra de 1949, señala: en caso de conflicto armado que no sea de índole internacional y que surja en el territorio de una de las Altas Partes Contratantes, cada una de las Partes en conflicto tendrá la obligación de aplicar, como mínimo, las siguientes disposiciones:

1) Las personas que no participen directamente en las hostilidades, incluidos los miembros de las fuerzas armadas que hayan depuesto las armas y las personas puestas fuera de combate por enfermedad, herida, detención o por cualquier otra causa, serán, en todas las circunstancias, tratadas con humanidad, sin distinción alguna de índole desfavorable basada en la raza, el color, la religión o la creencia, el sexo, el nacimiento o la fortuna o cualquier otro criterio análogo.

A este respecto, se prohíben, en cualquier tiempo y lugar, por lo que atañe a las personas arriba mencionadas:

a) los atentados contra la vida y la integridad corporal, especialmente el homicidio en todas sus formas, las mutilaciones, los tratos crueles, la tortura y los suplicios; 
b) la toma de rehenes;

c) los atentados contra la dignidad personal, especialmente los tratos humillantes y degradantes;

d) las condenas dictadas y las ejecuciones sin previo juicio ante un tribunal legítimamente constituido, con garantías judiciales reconocidas como indispensables por los pueblos civilizados.

2) Los heridos y los enfermos serán recogidos y asistidos.

Un organismo humanitario imparcial, tal como el Comité Internacional de la Cruz Roja, podrá ofrecer sus servicios a las Partes en conflicto.

Además, las Partes en conflicto harán lo posible por poner en vigor, mediante acuerdos especiales, la totalidad o parte de las otras disposiciones del presente Convenio.

La aplicación de las anteriores disposiciones no surtirá efectos sobre el estatuto jurídico de las Partes en conflicto.

\section{Caracterización de un conflicto armado interno}

El artículo 3, común a los cuatro Convenios de Ginebra, marcó un gran avance ya que abarca los conflictos armados no internacionales, que nunca antes habían sido incluidos en los tratados. Estos conflictos pueden ser de diversos tipos. Puede tratarse de guerras civiles, conflictos armados internos que se extienden a otros Estados, o conflictos internos en los que terceros Estados o una fuerza internacional intervienen junto con el gobierno.

El artículo 3 común establece las normas fundamentales que no pueden derogarse. (...), contiene las normas esenciales de los Convenios de Ginebra en un formato condensado y las hace aplicables a los conflictos sin carácter internacional:

- Establece que se debe tratar con humanidad a todas las personas que no participen en las hostilidades o que caigan en poder del adversario, sin distinción alguna de índole desfavorable. Prohíbe específicamente los atentados contra la vida, las mutilaciones, la toma de rehenes, la tortura, los tratos humillantes, crueles y degradantes, y dispone que deben ofrecerse todas las garantías judiciales.

- Establece que se debe recoger y asistir a los heridos y los enfermos. Concede al $\mathrm{CICR}^{7}$ el

Comité Internacional de la Cruz Roja. El CICR, fundado en 1863, trabaja en todo el mundo para prestar ayuda humanitaria a las personas afectadas por los conflictos y la violencia armada, y para promover las leyes por las que se protege a las víctimas de la guerra. Es una Institución independiente y neutral, su cometido dimana esencialmente de los Convenios de Ginebra de 1949. Sita en Ginebra, Suiza, emplea a unas 12.000 personas en 80 países; su financiación 
derecho a ofrecer sus servicios a las partes en conflicto.

- Insta a las partes en conflicto a poner en vigor, mediante acuerdos especiales, la totalidad o partes de los Convenios de Ginebra.

- Reconoce que la aplicación de esas normas no afecta el estatuto jurídico de las partes en conflicto.

Dado que la mayor parte de los conflictos armados actuales no son de carácter internacional, es de suma importancia aplicar el artículo 3 común. Es necesario que se lo respete plenamente.

Se considera que el Artículo 3 común a los cuatro Convenios de Ginebra de 1949, es una especie de convenio en miniatura. Incluso añadiéndole las disposiciones del Protocolo II, las normas por las que se rigen los conflictos internos son menos elaboradas que las normas por las que se rige el conflicto armado internacional. La dificultad con la que se tropieza para mejorar el régimen de protección en los conflictos armados no internacionales es el obstáculo que presenta el principio de la soberanía del Estado.

El derecho internacional humanitario no se aplica a las situaciones de violencia interna que no alcancen la intensidad de un conflicto armado. En ese caso, se pueden invocar las disposiciones del derecho de los derechos humanos, así como la legislación interna. El derecho

estriba principalmente en los donativos voluntarios procedentes de los Gobiernos y de las Sociedades Nacionales de la Cruz Roja y de la Media Luna Roja. El CICR se fundó a raíz de la labor que desempeñó el suizo Henry Dunant en la batalla de Solferino (1859), cuando organizó la atención indiscriminada en favor soldados franceses y austriacos desprovistos de asistencia médica pertinente.

El libro de Dunant, Recuerdo de Solferino (1862), indujo a la aprobación del primer Convenio de Ginebra (1864), en el cual se sentaron las normas para proteger a los soldados heridos y al personal sanitario, así como al establecimiento de sociedades de socorro en cada país. Estos organismos se llegaron a conocer como Sociedades de la Cruz Roja, en referencia al emblema universal aprobado para identificar y proteger las unidades sanitarias. (El emblema de la media luna roja se introdujo en el decenio de 1880) Desde su fundación, el CICR ha desempeñado un cometido humanitario en la mayoría de los conflictos que se han librado en todo el mundo. No ha cejado en trabajar para persuadir a los Estados de extender la protección jurídica de las víctimas de la guerra, a fin de limitar el sufrimiento.

El CICR, las Sociedades Nacionales y su Federación Internacional integran el Movimiento Internacional de la Cruz Roja y de la Media Luna Roja. En situaciones de conflicto armado, el CICR coordina la acción de sus asociados del Movimiento. Al CICR se le ha otorgado un cometido internacional permanente para realizar su labor. Se deriva de los Convenios de Ginebra de 1949 -que gozan de aceptación de todos los Estados- y de los Estatutos del Movimiento. Sin embargo, el CICR es una institución privada regida por el derecho suizo; es estrictamente independiente en su gobierno y en sus decisiones relativas a las actividades operacionales. El Comité propiamente dicho está integrado por 25 miembros cooptados, los cuales son todos suizos. La labor del CICR observa los Principios Fundamentales del Movimiento, especialmente los de neutralidad, imparcialidad e independencia.

La acción del CICR se funda en los Convenios de Ginebra de 1949 y sus Protocolos adicionales, así como en los Estatutos de la Institución -y los del Movimiento Internacional de la Cruz Roja y de la Media Luna Roja- y las resoluciones de la Conferencia Internacional de la Cruz Roja y de la Media Luna Roja. El CICR es una organización independiente y neutral que se esfuerza por prestar protección y asistencia humanitarias a las víctimas de los conflictos armados y las de otras situaciones de violencia. Toma medidas para responder a las emergencias y promueve, al mismo tiempo, el respeto del derecho internacional humanitario y su aplicación en la legislación nacional. 
internacional humanitario y el derecho internacional de los derechos humanos (en adelante, los derechos humanos) son complementarios. La finalidad de ambos es proteger la vida, la salud y la dignidad de la persona humana, aunque desde ángulos diferentes.

El derecho humanitario se aplica en situaciones de conflicto armado, mientras que los derechos humanos o, al menos, algunos de ellos protegen a la persona humana en todo tiempo, haya guerra o paz. Sin embargo, algunos tratados de derechos humanos autorizan a los gobiernos a suspender ciertos derechos en situaciones de emergencia pública. El DIH no admite derogación alguna, dado que fue concebido para situaciones de emergencia, en particular los conflictos armados.

La finalidad del derecho humanitario es proteger a las personas que no participan -o han dejado de participar- en las hostilidades. Las normas incluidas en el DIH imponen deberes a todas las partes en conflicto. Los derechos humanos, concebidos fundamentalmente para tiempos de paz, se aplican a todos. Su principal objetivo es proteger a las personas contra la arbitrariedad de su respectivo gobierno. Estos derechos no regulan la conducción de las hostilidades.

El deber de velar por que se apliquen el DIH y los derechos humanos incumbe principalmente a los Estados. En virtud del derecho humanitario, los Estados tienen la obligación de adoptar medidas prácticas y jurídicas, como son la promulgación de leyes penales y la difusión del DIH.

Paralelamente, a tenor del derecho de los derechos humanos, los Estados velarán por que su legislación nacional esté en conformidad con las obligaciones internacionales. En el DIH se prevén varios mecanismos específicos para contribuir a su aplicación. En particular, los Estados han de garantizar que los demás Estados también lo respeten. Asimismo, están previstos un procedimiento de encuesta, un mecanismo de Potencia protectora y la Comisión Internacional de Encuesta.

\subsection{Protocolo II adicional a los Convenios de Ginebra de 1949 relativo a la protección} de las víctimas de los conflictos armados sin carácter internacional, 1977

\section{Artículo 1. Ámbito de aplicación material}

1. El presente Protocolo, que desarrolla y completa el artículo 3 común a los Convenios de Ginebra del 12 de agosto de 1949, sin modificar sus actuales condiciones de aplicación, se aplicará a todos los conflictos armados que no estén cubiertos por el artículo 1 del Protocolo adicional a los Convenios de Ginebra del 12 de agosto de 1949 en lo relativo a la protección de las víctimas de los conflictos armados internacionales (Protocolo I) y que se desarrollen en el 
territorio de una Alta Parte contratante entre sus fuerzas armadas y fuerzas armadas disidentes o grupos armados organizados que, bajo la dirección de un mando responsable, ejerzan sobre una parte de dicho territorio un control tal que les permita realizar operaciones militares sostenidas y concertadas y aplicar el presente Protocolo.

2. El presente Protocolo no se aplicará a las situaciones de tensiones internas y de disturbios interiores, tales como los motines, los actos esporádicos y aislados de violencia y otros actos análogos, que no son conflictos armados. ${ }^{8}$

\section{Interpretación:}

El Protocolo II no define CANI, define UN TIPO de CANI (básicamente, aquél en el cual el grupo armado organizado tiene control territorial). En los casos donde el control territorial no se verifica, sigue aplicándose el artículo 3 común. Por lo tanto, la definición del Protocolo II no es general, sólo es válida para la aplicación de dicho instrumento.

El CANI, se caracteriza por el enfrentamiento entre:

- Las FFAA de un Estado y las fuerzas disidentes o rebeldes. Este es solo uno de los casos señalados en el Protocolo II; faltan los conflictos que surgen entre las fuerzas armadas del Estado y grupos armados organizados. Se exceptúan de ello, a las situaciones de tensiones internas y de disturbios interiores, tales como motines, los actos esporádicos y aislados de violencia y otros actos análogos, estos no son considerados como conflictos armados.

La vigilancia del DIH descansa en el Comité Internacional de la Cruz Roja (CIRC). El cometido del CICR, como promotor y guardián del derecho internacional humanitario, es promover el respeto de ese derecho. Para ello, da a conocer las normas del derecho humanitario y recuerda a las partes en conflicto las obligaciones contraídas.

La colaboración con el Comité Internacional de la Cruz Roja (CICR), institución a la cual la comunidad internacional ha otorgado el mandato de promover y de actuar como guardián del derecho internacional humanitario, resulta de suma importancia para lograr el pleno respeto de las normas destinadas a proteger la vida y la dignidad de las víctimas de la guerra y de otras situaciones de violencia.

Todos los Estados tienen la responsabilidad de acatar los Convenios de Ginebra y sus protocolos adicionales. Asimismo, la de plasmar el derecho internacional humanitario en la legislación nacional aplicable a las situaciones que abarca este ordenamiento jurídico, así como de velar por su total respeto y aplicación, cuando proceda.

8 Para este tipo de situaciones se invocan disposiciones constitucionales y de derechos humanos. 
¿El sindicar el caso del VRAE como conflicto armado interno es otorgarle a los "Quispe Palomino" como fuerzas beligerantes, y/o guerrilleros? ¿`Son insurgentes?

La respuesta es no. Recordemos que el informe de la Comisión de la Verdad calificó a la lucha contra la subversión como un conflicto armado interno entre los años 80 y 2000, el más sangriento de toda la historia republicana, causante en la población de graves secuelas, como trastornos psicológicos, sentimientos del temor y odio, así como una grave limitación en el desarrollo de la personalidad sobre todo en las víctimas del terrorismo.

Pese a la calificación de conflicto armado interno y la aplicación del DIH, los terroristas no recibieron la categorización de "beligerantes" o "insurgentes" y fueron procesados y condenados por delitos comunes en aplicación del código penal en el rubro de graves violaciones a los derechos humanos. Esta condición solo la otorga el Estado en el marco de su facultad discrecional. Colombia vive un conflicto armado interno por más de medio siglo, y el Estado no reconoce que la FARC sea una agrupación insurgente y menos beligerante, precisamente por sus procedimientos. Estos grupos no son beligerantes, aun cuando siempre demanden ese trato, pues no son respetuosos del Derecho Internacional Humanitario, y en sus acciones utilizan métodos condenados por el derecho internacional, como la toma de rehenes, secuestros, asesinatos, atentados con explosivos, etc. Estos métodos constituyen conductas sancionables por el Derecho Penal interno de los Estados. Los terroristas no tiene derecho al tratamiento de prisioneros de guerra y los Estados no están obligados a observar para con ellos un tratamiento diferente al que corresponde a los criminales de derecho común.

Ahora bien, es conveniente señalar que el actual código penal no cuenta con una tipificación sobre delitos contra el derecho internacional humanitario; existe un proyecto de adecuación del Estatuto de Roma al código penal pero es una iniciativa política que el Congreso de la República no da curso desde el año 2003. Sería conveniente, a la luz de los hechos, que el parlamento adoptase la decisión política de aprobar este proyecto aun en el seno de la Comisión de Justicia y Derechos Humanos.

Una razón adicional por la que los terroristas del MRTA y los de la FARC, para citarlos como ejemplo, no pueden ser considerados beligerantes ni insurgentes procede de la lista de personas y grupos armados y organizados catalogados como "terroristas" por el Consejo de Ministros de la Unión Europea, actualizada al 2008. En dicha lista se incluye a Sendero Luminoso, al MRTA y a las FARC. Sus procedimientos constituyen delitos de carácter internacional que los estados miembros de las Naciones Unidas se han comprometido a erradicar.

La profesora Elizabeth Salmón Garate, en su obra Introducción al Derecho Internacional Humanitario (pagina 119), señala (...) teniendo en cuenta que las normas contenidas 
en el artículo $3^{\circ}$ común a los Convenios de Ginebra constituyen un estándar mínimo de protección , al adoptarse esta disposición se confirió a las partes la posibilidad de elevar dicho estándar a través de las adopción de acuerdos especiales o humanitarios que permitan poner en vigor, total o parcialmente, el respeto de disposiciones de los Convenios de Ginebra (...). Lo cierto es que ni la adopción de acuerdos ni la aplicación del artículo $3^{\circ}$ común significan un reconocimiento de un estatuto jurídico a las partes enfrentadas, por cuanto el propósito de este artículo es brindar, por razones humanitarias, protección a las victimas del conflicto.

El reconocimiento de beligerancia obedece a la comprobación de respeto y observancia de las normas internacionales, pero es una facultad discrecional de los Estados y no es aplicable al caso concreto que se analiza.

La insurgencia no está dentro del ámbito de aplicación del DIH. La Constitución del Perú, en su artículo $46^{\circ}$ reconoce el derecho de insurgencia de la población civil pero en defensa del orden constitucional. Los terroristas no pueden ser catalogados como insurgentes porque ellos no defienden el orden constitucional, por el contrario, amenazan el orden jurídico constitucional y buscan la escisión del Estado, desestabilizando al gobierno.

Al tiempo de escribir este artículo9 y como era previsible, los ministros del Interior y de Defensa, Daniel Lozada Casapía y Alberto Otárola Peñaranda, respectivamente, presentaron su renuncia irrevocable, según un comunicado de la Presidencia de Consejo de Ministros. Se informó que el presidente del Consejo de Ministros, Oscar Valdés Dancuart, conforme a lo dispuesto en el artículo $122^{\circ}$ de la Constitución Política, ha procedido al trámite correspondiente ante el Despacho Presidencial. Siendo ello así, el costo político ha sido cumplido en parte. Las renuncias se debieron formular mucho antes, y no cuando se estaba ya al borde de una censura política: "una terquedad que ha conducido a un escenario lamentable e indigno".

\footnotetext{
9 Jueves 10 de mayo 2012.
} 


\section{REFLEXIONES FINALES}

- La renuncia de los ministros no implica hacerle el juego al "terrorismo", es una respuesta a la sociedad y sobre todo a las familias de los deudos que claman justicia. A partir de ahora, habría que reformular la conducción y estrategia de las operaciones de carácter militar en la zona del VRAE, con el desplazamiento urgente de la población civil de la zona de conflicto. Hubo una evidente responsabilidad política que merecía una sanción. Habremos perdido una batalla pero no el conflicto. El gobierno debería reconocer el error político de esta situación y garantizar que "nadie tiene corona en este país", simplemente al "hecho su consecuencia".

- A partir de estos momentos vamos a ingresar a un verdadero combate en la zona del VRAE, y será inevitable que mueran combatientes, lo que no debe derivar a posteriori en procesos judiciales contra quienes arriesgan su vida por darnos la paz y la tranquilidad, como se vio en el caso de la exitosa operación Chavín de Huántar.

- Se espera un Estado fuerte y decidido para combatir el narcotráfico, el terrorismo y la corrupción. El Estado puede ejercer un mayor control del narcotráfico y así reducir a su mínima expresión al terrorismo. Para ello se requiere incrementar las acciones de inteligencia nacional.

- Asimismo, se tienen que tomar medidas urgentes para evitar que surjan en el Perú generaciones revolucionarias con el ánimo de desestabilizar la estructura del poder político. Esto obedece al hecho mismo que se han violados mujeres para procrear "futuros revolucionarios", lo que ha motivado la denuncia del Estado peruano ante el Comité de los Derechos Sociales, Económicos y Culturales de las Naciones Unidas, así como el pronunciamiento del Fondo de las Naciones para la Infancia (UNICEF). A esto se suma el adoctrinamiento de niños con ideologías ultra radicalistas propias de Sendero Luminoso. Desde la captura de Abimael Guzmán, conocido como el "presidente Gonzalo", líder del grupo terrorista, han transcurrido 20 años aproximadamente y se pensó que se había culminado esa "lucha", los gobiernos sucesivos no se esforzaron por eliminar lo que ellos mismos llaman "remanentes", algo de lo que no estoy tan segura, es decir, que se trate tan solo de remanentes. Consecuentemente, creo que si no se adoptan medidas urgentes al respecto, probablemente en los próximos años tendremos nuevamente subversión. Esperemos que ello no sea así por la paz de todos los peruanos.

- La ausencia de dialogo, la ausencia del Estados en las zonas más vulnerables del país, han conllevado a la proliferación de conflictos sociales y a que los narcoterroristas sometan muchas poblaciones civiles (sobre todo a las que viven en extrema pobreza) mediante la satisfacción de sus necesidades, cuando eso es responsabilidad del Estado. Indicadores 
que amenazan la institucionalidad democrática, cuando por parte del Estado no se exhibe capacidad para enfrentar el reto.

- El Estado de Derecho y el Principio de Autoridad deben imponerse de manera soberana, de tal modo que los reclamos se puedan ver en las instancias que correspondan, y no mediante prácticas ilegales y punibles que deben ser literalmente desterradas de los procedimientos para alcanzar objetivos de grupos particulares. (Minerías ilegales).

- Fortalecer la conceptualización de democracia como forma de gobierno y de vida. Debemos concebir la democracia como "derecho fundamental de las personas, de todos los peruanos".

- La democracia es indispensable para el ejercicio efectivo de las libertades fundamentales y los derechos humanos, en su carácter universal, indivisible e interdependiente, como está consagrada en las respectivas constituciones de los estados y en los instrumentos interamericanos e internacionales de derechos humanos.

- El liderazgo político implica, dentro de su compleja conceptualización, "la idoneidad para gobernar"; es decir, la proyección de la capacidad y/o competitividad de una persona para representar los intereses de una nación. Un líder tiene verdadera vocación de servicio y el suficiente nivel de conciencia de que ha sido elegido para representar los intereses de una nación.

- Una buena gobernabilidad se da sobre la base de la concertación política de los partidos, instituciones democráticas, órganos y poderes del Estado, sectores de la sociedad de forma amplia y no reducida a las ONGs. Un foro importante y poco aprovechado son las Universidades "canteras del quehacer jurídico-politico"; las universidades son foros por excelencia de "docencia política". Los partidos son y deben seguir siendo los primeros "defensores" del orden constitucional y democrático en la nación.

- El Estado peruano tiene la obligación de respetar los derechos de la colectividad, principalmente de los peruanos que fueron víctimas de la subversión y del terrorismo en las zonas más pobres del país. Ellos también tienen dignidad y derecho a una reparación por el daño que se les ha ocasionado.

- Las decisiones firmes, justas y proporcionadas hacen que las instituciones democráticas también se fortalezcan. El Estado y la sociedad son corresponsables de la promoción y difusión de los derechos humanos.

- Se precisa un Estado fuerte y decido para emprender un gran cambio: "el perfeccionamiento de su propio sistema judicial interno", y de adoptar medidas firmes que al tiempo de reconocer la importancia de los órganos supranacionales de protección de derechos humanos, haga 
prevalecer los derechos de todos los ciudadanos peruanos, respetando su dignidad frente a decisiones internacionales cuyos componentes resultasen excesivos, desnaturalizando su propio funcionamiento. Hace falta una alianza política o un pacto politico concertado para enfrentar esta dura realidad.

- Establecer el respeto por el Estado de Derecho es fundamental para lograr una paz duradera después de un conflicto, para proteger eficazmente los derechos humanos y para lograr progreso y desarrollo económico sostenidos.

\section{REFERENCIAS BIBLIOGRÁFICAS}

1. Curso introductorio sobre Derecho Internacional Humanitario, organizado por la Oficina de Derecho Internacional de la OEA. Contiene, además, el texto íntegro de los cuatro Convenios de Ginebra. 2007.

2. Salmón Garate, Elizabeth. Introducciónal Derecho Internacional Humanitario. IDEHPUCPCICR, Lima, 2004. 174 pág.

3. Coll, Pilar, Informe final de la CVR-ejes temático de las conclusiones, Instituto Bartolomé de las Casas, 2003.

4. Comité Internacional de la Cruz Roja, Derecho Internacional Humanitario: respuestas a sus preguntas, CICR, Ginebra, 2007.

5. Comité Internacional de la Cruz Roja, Diccionario de Derecho Internacional de los Conflictos Armados, CICR, Ginebra, 1998

6. Comité Internacional de la Cruz Roja, Normas fundamentales de los Convenios de Ginebra $y$ de sus dos protocolos adicionales. Conociendo el DIH, CICR, 1983.

7. Comité Internacional de la Cruz Roja, Los Cuatro Convenios de Ginebra del 12 de agosto de 1949, Ginebra, 1986.

8. Comité Internacional de la Cruz Roja, Protocolos adicionales a los Convenios de Ginebra, 1986.

9. MOCIÓN DE CENSURA No 2047

\section{LINK consultado:}

http://www.icrc.org/spa/war-and-law/treaties-customary-law/geneva-conventions/ overview-geneva-conventions.htm 